University of Wollongong

Research Online

Faculty of Informatics - Papers (Archive)

Faculty of Engineering and Information

Sciences

$1-1-2009$

\title{
Voltage quality behaviour of a wind turbine based remote area power system
}

Nishad Mendis

University of Wollongong, nnrm786@uowmail.edu.au

Kashem Muttaqi

University of Wollongong, kashem@uow.edu.au

Sarath Perera

University of Wollongong, sarath@uow.edu.au

Follow this and additional works at: https://ro.uow.edu.au/infopapers

Part of the Physical Sciences and Mathematics Commons

\section{Recommended Citation}

Mendis, Nishad; Muttaqi, Kashem; and Perera, Sarath: Voltage quality behaviour of a wind turbine based remote area power system 2009, 1-6.

https://ro.uow.edu.au/infopapers/1604

Research Online is the open access institutional repository for the University of Wollongong. For further information contact the UOW Library: research-pubs@uow.edu.au 


\title{
Voltage quality behaviour of a wind turbine based remote area power system
}

\begin{abstract}
The power quality behaviour of a Remote Area Power System (RAPS) consisting of a Doubly Fed Induction Generator (DFIG), its main loads and a dummy load is presented in this paper. The dummy load is used to maintain the power balance of the system under changing wind and loading conditions. The performance of the remote area power system subject to various loading conditions has been evaluated in terms of the voltage quality, an aspect which has not received much attention in the past. The existing Distributed Generation (DG) power quality standards are taken as the basis to compare the voltage quality of the simulated waveforms. The simulation results indicate that the system evaluated is able to maintain the load bus bar voltage and frequency within tight limits whereas a better harmonic performance can be achieved if adequate filtering is employed. The model was developed using SimPowerSystem tool box in MATLAB.
\end{abstract}

\section{Keywords}

Voltage, quality, behaviour, wind, turbine, based, remote, area, power, system

\section{Disciplines}

Physical Sciences and Mathematics

\section{Publication Details}

N. Mendis, K. Muttaqi \& S. Perera, Voltage quality behaviour of a wind turbine based remote area power system, in IEEE Conference on Industrial Technology, 2009 (ICIT 2009), pp. 1-6. 


\title{
Voltage Quality Behaviour of a Wind Turbine Based Remote Area Power System
}

\author{
Nishad Mendis, Kashem M. Muttaqi and Sarath Perera \\ School of Electrical, Computer Engineering and Telecommunication Engineering \\ University of Wollongong \\ Australia \\ Emails:nnrm786@uow.edu.au,kashem@uow.edu.au and sarath@uow.edu.au
}

\begin{abstract}
The power quality behaviour of a Remote Area Power System (RAPS) consisting of a Doubly Fed Induction Generator (DFIG), its main loads and a dummy load is presented in this paper. The dummy load is used to maintain the power balance of the system under changing wind and loading conditions. The performance of the remote area power system subject to various loading conditions has been evaluated in terms of the voltage quality, an aspect which has not received much attention in the past. The existing Distributed Generation (DG) power quality standards are taken as the basis to compare the voltage quality of the simulated waveforms. The simulation results indicate that the system evaluated is able to maintain the load bus bar voltage and frequency within tight limits whereas a better harmonic performance can be achieved if adequate filtering is employed. The model was developed using SimPowerSystem tool box in MATLAB.
\end{abstract}

\section{INTRODUCTION}

Remote area power supply (RAPS) systems have gained popularity over the years as viable schemes to provide power to rural and regional communities including islands where grid supply is not available. Such schemes may consist of a combination of one or more renewable energy sources making them hybrid systems. Such systems are superior to conventional generating systems in terms of efficiency, reduction of environmental impact and generation cost [1]. One of the major issues associated with such a power system is the quality of power which is delivered to the end users. Poor voltage and frequency regulation, presence of harmonics at the point of generation and Point of Common Connection (PCC), voltage unbalance and flicker are identified as the major power quality problems in a RAPS system.

There are no dedicated power quality standards with regard to power quality associated with RAPS systems. Two standards that may be used in relation to RAPS are IEEE 5191992 and AS/NZS61400.21 [2]- [3], latter being a standard specific to wind turbine generating systems. The IEEE 1574 standard provides a uniform criteria and requirements relevant to the performance, operation, testing, safety considerations and maintenance of grid connected Distributed Generation (DG) technologies up to $10 \mathrm{MW}$. Even with the grid connected DG systems the connection rules and technical requirements are still a major subject of research.

Of the several renewable options available for remote power systems, wind energy is identified as an excellent renewable energy option. There are several wind power generation technologies available to extract power from the wind. Among the variety of the wind turbine generating systems, DFIG has become a popular technology for high power grid connected wind applications. It offers many advantages over other types of wind turbines. Power electronic converter rating is limited to about $20-30 \%$ of the total capacity of the system, maximum power extraction capability in variable wind conditions and ability to generate power at sub-synchronous and supersynchronous modes are the most attractive features of a DFIG system [4]. The application of DFIG in RAPS environment has received only little attention. In this regard, the DFIG itself should be able to regulate the magnitude of the voltage and the frequency irrespective of the rotational speed of the shaft and the loading conditions. [5] - [6] suggest a methodology to regulate the stator voltage magnitude and the frequency through vector control mechanisms. These propose the adoption of Indirect Stator Flux Oriented (ISFO) vector control approach for the Rotor Side Controller (RSC). The Indirect Stator Voltage Oriented (ISVO) vector control scheme is proposed for the Line Side Controller (LSC) which is used to control the DC link voltage while providing additional reactive power to the system when necessary.

This paper discusses the voltage quality of a remote area power system in terms of the bandwidth of the voltage regulation capability and harmonic content of the voltage of the RAPS system. A simplified schematic of such a remote power system is shown in Fig. 1. This consists of a DFIG as the only generator, main load, a dummy load as a secondary load and its controller. The dummy load controller is designed to absorb the instantaneous excessive power available that would otherwise can cause unacceptable voltage and frequency excursions. The RAPS operation has been examined under rated conditions and with step load changes. Also the transient and steady state response of the remote power system is evaluated in relation to an Induction Motor (IM) as a part of the load. The harmonic performance of the RAPS system is also presented.

The paper is organized as follows. Section II briefly outlines the control methodology of the DFIG based remote area power system. Section III discusses the response of the DFIG under fluctuating wind conditions while supplying: (a) fixed 


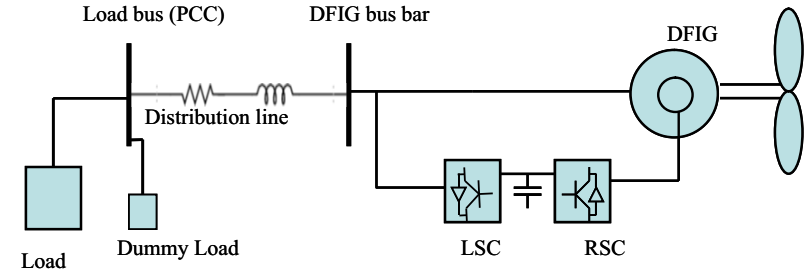

Fig. 1. Remote area power system with DFIG based wind turbine

load (b) variable load and (c) induction motor load. The harmonic behaviour of the system is discussed in Section IV. Conclusions are given in the Section V.

\section{Control of Voltage And Frequency for STAND-ALONE DFIG SYSTEM}

The DFIG has been modelled in $\mathrm{d}-\mathrm{q}$ reference frame. Vector control has been applied to the RSC and the LSC. The mathematical model of the DFIG in an arbitrary rotating reference as described in [7] is employed in the present work. The RSC is used to regulate the stator voltage magnitude and the frequency. The LSC is a conventional arrangement which is used to control the DC link voltage and provide additional reactive power to the load when necessary. A Phase Lock Loop (PLL) is used to define the frequency of the RAPS system and the orientation angles in relation to the RSC and LSC.

\section{A. Rotor Side Controller(RSC)}

Indirect stator flux oriented vector control is adopted in controlling the the RSC. (1) and (2) are used to derive the appropriate vector current control methodology to regulate the frequency and the magnitude of the stator voltage respectively [8].

$$
i_{r q}=-\frac{L_{s}}{L_{m}} i_{s q}
$$

where,

$i_{r q}, i_{s q}$ - rotor and stator q-axis current respectively, $L_{s}, L_{m}$ - stator inductance and magnetising inductance respectively

$$
\frac{L_{s}}{R_{s}} \frac{d i_{m s}}{d t}+i_{m s}=i_{r d}+\frac{v_{s d} L_{s}}{R_{s} L_{m}}
$$

where,

$R_{s^{-}}$stator resistance, $i_{m s^{-}}$stator magnetising current, $v_{s d^{-}}$ stator d-axis voltage, $i_{r d^{-}}$rotor d-axis current

In steady state the machine flux level (ie. determined by $\left.i_{m s}\right)$ is constant. Also, the stator resistance is relatively small and can be neglected. Hence $v_{s d}$ is assumed to be zero. Therefore, (2) can be further simplified to (3).

$$
i_{m s} \approx i_{r d}
$$

\section{B. Line Side Controller (LSC)}

The line side controller is a conventional arrangement as presented in [8]. As stated earlier, the stator voltage is controlled by the RSC. Therefore the stator voltage is readily available for the LSC as a controlled input if required. However, the stator voltage is affected by the power quality parameters on the line side (ie. load). Therefore the line side voltage should not be used to derive the orientation angle for the LSC. For this reason, (4) is used to fix the orientation angle for the LSC [8]. This approach helps to avoid the influence of the power quality disturbances (eg. harmonics) on the performance of the line side controller.

$$
\theta_{v}=\theta_{s}+\frac{\pi}{2}
$$

where,

$\theta_{v^{-}}$new orientation angle, $\theta_{s^{-}}$orientation angle derived from PLL

\section{Dummy Load Controller}

A dummy load is incorporated in to the RAPS system so that it absorbs the instantaneous excessive power associated with the entire system. The condition under which it operates is given by (5).

$$
P_{\text {dummy }}=P_{D F I G}-P_{\text {load }}>0
$$

where,

$\mathrm{P}_{\text {dummy }}$ dummy load power, $\mathrm{P}_{D F I G^{-}}$total power output of the DFIG, $\mathrm{P}_{\text {load }}$ - load demand

The dummy load controller measures the output frequency $\left(f_{R A P S}\right)$ and it compares with the reference frequency $\left(f_{r e f}\right)$ (ie. $50 \mathrm{~Hz}$ ). This error is compensated through a PID controller and the output signal is fed to the dummy load. The dummy load consists of a series of resistors which are connected together with switches. The switches operate in accordance with the control signals generated by the controller. A simplified control scheme of the dummy load controller is shown in Fig. 2 [9].

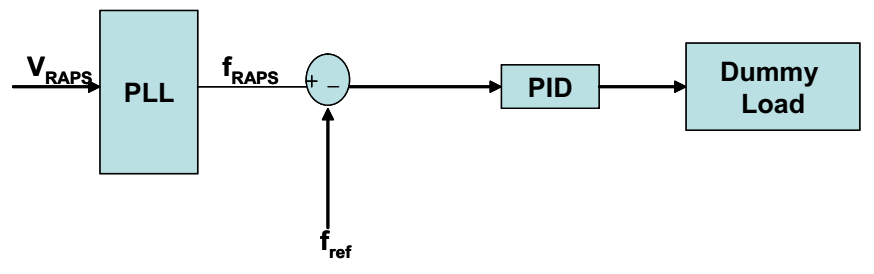

Fig. 2. Dummy load controller

\section{Response of the Remote Area Power System WITH DFIG BASED WIND TURBINE}

The RAPS in Fig. 1 is studied to examine its performance under (a) fluctuating wind and fixed load (b) fluctuating wind and step load. The parameters of the components of this power 
system are listed in Appendix A. It is assumed that the DFIG can supply the total load demand together with the dummy load. The entire system has been simulated to represent nearly rated wind conditions $(11 \mathrm{~m} / \mathrm{s})$.

\section{A. Fluctuating Wind with Fixed Load (Resistive)}

Simulation results corresponding to fluctuating wind conditions while the RAPS system is supplying a constant power load (nominal $500 \mathrm{~kW}$ ) are shown in Fig. 3. Fig. 3-(a) shows the fluctuating wind speed and Fig. 3-(b) indicates the super synchronous mode of operation corresponding to nearly constant speed of $1.1 \mathrm{pu}$. The stator voltage profile is shown in Fig. 3 -(c). The stator voltage lies approximately within $\pm 2 \%$ of the rated value. This variation can be justified by considering (2) which is used to control the voltage by setting up the machine flux level via controlling $i_{r d}$ of the rotor (noting that the stator resistance is neglected as mentioned earlier). Therefore the machine flux level (ie. corresponding to $i_{m s}$ ) fixes the stator voltage within above mentioned bandwidth. The frequency on the load side is shown in Fig.3-(d) which varies approximately within $49.8 \mathrm{~Hz}$ to $50.2 \mathrm{~Hz}$. As stated earlier the frequency of the system is governed by (1). The frequency of the system is achieved by the proper alignment of orientation angles of the variables associated with RSC and LSC (ie. angles defined by the $\mathrm{d}$ and q components of the flux and voltage). Frequency fluctuations are expected due to the non-coincidence of the real orientation angles with virtual orientation angles defined by the PLL. It is important to note that the real orientation angles are affected by the power quality parameters (eg. harmonics) of the system. Also the load fluctuations of RAPS can contribute to frequency fluctuations as indicated by the relationship between power and the frequency given by (6).

$$
\Delta f=\frac{\Delta P}{M s+D}
$$

where,

$\Delta f$ - frequency deviation, $\Delta P$ - active power variation, $M$ - inertia constant, $D$ - load damping constant

The term $\Delta P$ in (6) represents the instantaneous power fluctuation of the RAPS system due to the action of the dummy load controller. Referring to (6), it can be seen that the instantaneous power absorption level of the dummy load as shown in Fig. 3-(g) correlates well with frequency fluctuations in the RAPS system. The maximum frequency deviation occurs when the dummy load power is at its maximum value (ie. at 1.8 seconds). The DC link voltage of the back-back converters in Fig. 1 is designed to operate at 1000 V. The simulated results are shown in Fig. 3-(e) indicating variations between $995 \mathrm{~V}$ and $1005 \mathrm{~V}$ which is anticipated due to the operation of the back-back converters together with power imbalance arises between RSC and LSC. In super synchronous mode of operation RSC acts as a rectifier and LSC acts as an inverter. At any slip 's' of the DFIG, the interaction between the rectifier and inverter harmonics cause unwanted DC current pulsations at the DC link causing a variable DC link voltage as evident from Fig. 3-(e). The harmonic frequencies of the DC link current is given by (7) and (8) [10]. Fig. 3-(f) shows the power delivered to the total load. The total power output consists of two components corresponding to the main load and the dummy load. The fluctuating voltage at load bus and the dummy load leads to power fluctuations as depicted in Fig. 3-(f).

$$
\begin{array}{rlrl}
f_{d c, h}^{R} & =6 k|s| f_{s} & k=1,2,3 . . \\
f_{d c, h}^{I}=6 f_{s} m & m=1,2,3 . .
\end{array}
$$

where,

$\mathrm{f}_{d c, h^{-}}^{R}$ harmonics due to the rotor side controller, $\mathrm{f}_{d c, h^{-}}^{I}$ harmonics due to the line side controller, $\mathrm{f}_{s^{-}}$stator frequency, $|s|$ - slip of the DFIG

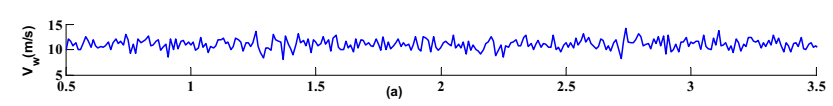
高 1.2
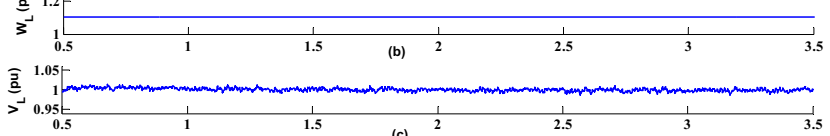

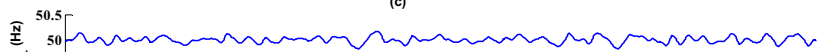
$\begin{array}{llllll}4 & 1.5 & \text { (d) } & 1 & 2.5 & 3\end{array}$

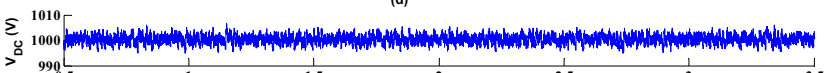

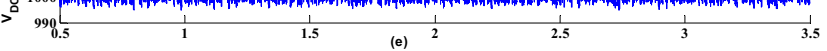

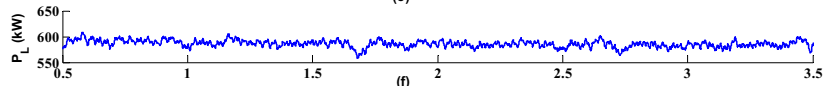
(9) Fig. 3. Responses of the RAPS system at variable wind, rated load condition.(a) Wind speed, (b) Turbine mechanical speed, (c) Stator voltage, (d) Stator frequency, (e) DC link voltage, (f) DFIG power output and (g) Dummy load power

\section{B. Fluctuating wind with variable load (resistive)}

The RSC is designed to regulate the voltage and the frequency of the system irrespective of changes in the loading conditions.

The frequency of the RAPS can be maintained at $50 \mathrm{~Hz}$ as long as the condition stated by (1) is satisfied. For example, during a resistive load step change $i_{r q}$ must change its magnitude in proportion to the $i_{s q}$ satisfying this condition. The simulated behaviour of $i_{r q}$ and $i_{s q}$ are shown in Fig. 4 for a step reduction in the load demonstrating that the ratio $\left(\frac{i_{r q}}{i_{s q}}\right)$ $\left(=\frac{L_{s}}{L_{m}}\right)$ maintains a constant value before and after the step change in the load. Based on the machine parameters listed in Appendix A, the above ratio is nearly equal to unity.

Figs. 5 and 6 show the magnitude and the frequency of the stator voltage for a step change in the resistive load. Fig. 5 corresponds to a $100 \mathrm{~kW}$ reduction in the load while the RAPS system is initially supplying a $600 \mathrm{~kW}$ resistive load. It can be seen that the voltage and the frequency of the RAPS system are not seen to be influenced by the load change. The voltage stays 
within $1 \pm 0.02$ p.u and the frequency stays within $50 \pm 0.05 \mathrm{~Hz}$. Fig. (6) shows the voltage and the frequency of the RAPS system corresponding to a load step up while it is supplying a $500 \mathrm{~kW}$ resistive load. The simulated results illustrate the behaviour in relation to the voltage and the frequency as in the case of load reduction. From the above results it can be concluded that the suggested controls associated with DFIG perform quite satisfactorily in maintaining the voltage and the frequency within acceptable limits during step changes in the load in relation to the case where the wind speed is fluctuating.

\section{Fluctuating wind together with an induction motor load}

The remote operation of the RAPS system supplying an induction motor load is investigated. The DFIG is now setup to provide the additional reactive power required by the load by setting a value for $i_{\text {sqref }}$ of the line side controller.

The DFIG is initially supplying a $350 \mathrm{~kW}$ resistive load. A $150 \mathrm{~kW}$ induction motor (Appendix B gives details) is directly connected to the system at 0.75 second. The corresponding line side behaviour is illustrated in Fig. 7. At the time of the connection, the induction motor draws a large current from the DFIG (215 A being the rated current) which primarily corresponds to a reactive component. This current leads to unwanted transients in all waveforms of the system. It is seen that initially the DFIG is not capable of supplying the required reactive power to the induction motor without facing major difficulties. Lack of reactive power leads to a voltage collapse in the RAPS system causing a voltage sag as evident from Fig. 7-(a). Naturally, the disturbance on the stator side of the DFIG is transferred to the rotor resulting both high rotor currents and voltages in the rotor side converter. The drop in the stator voltage linked with a reduction in real power delivery to the load makes the additional energy to return to the DC link and hence the DC link voltage is seen to rise to a high value of $1080 \mathrm{~V}$ as evident from Fig. 7-(c). As seen from Fig. 7(b), the frequency of the load side stays within $50 \pm 0.5 \mathrm{~Hz}$ while the maximum frequency deviation is seen to occur at approximately 0.84 seconds. The reason for such a deviation is that the RSC is attempting to provide the instantaneous active power requirement by injecting more $i_{r q}$ at 0.84 seconds. This results a slight increase in the frequency. Soon after the connection of the induction motor, LSC generates the required reactive power for the motor load as seen in Fig. 7-(e) and the stator voltage is restored and DFIG resumes normal operation.

According to the IEEE 1574 standard [2] the clearing time for low voltage DG systems subjected to a disturbance should be less than 0.16 seconds. In the scenario considered above, during the acceleration period of the motor, the voltage of the RAPS system varies between $0.62 \mathrm{pu}$ and $1.1 \mathrm{pu}$. The voltage recovery time is nearly 0.25 seconds as evident from Fig. 7-(a). However, it can be seen that the voltage recovery time is slightly longer than the maximum time setting as mentioned in the standard. The frequency of the RAPS system is within $50.42 \mathrm{~Hz}$ to $49.67 \mathrm{~Hz}$ during the motor acceleration. The allowed frequency deviation is typically in the range of $59.3 \mathrm{~Hz}$ to $60.5 \mathrm{~Hz}$ for a $60 \mathrm{~Hz}$ system [2]. It can be concluded that the RAPS system studied is able to perform reasonably well during the connection of a major induction motor load while maintaining the frequency. Some improvements are still required in relation to the clearing times.
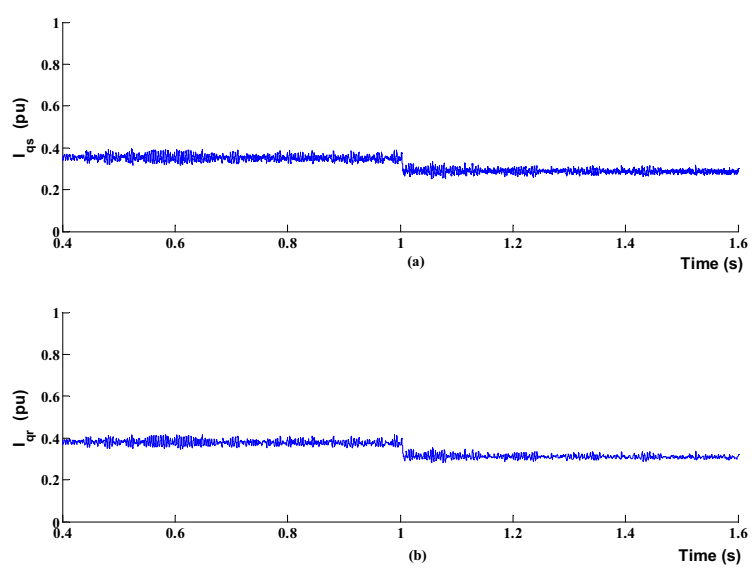

Fig. 4. "q" axis current for a step down load. (a) stator q-axis current, (b) Rotor d-axis current
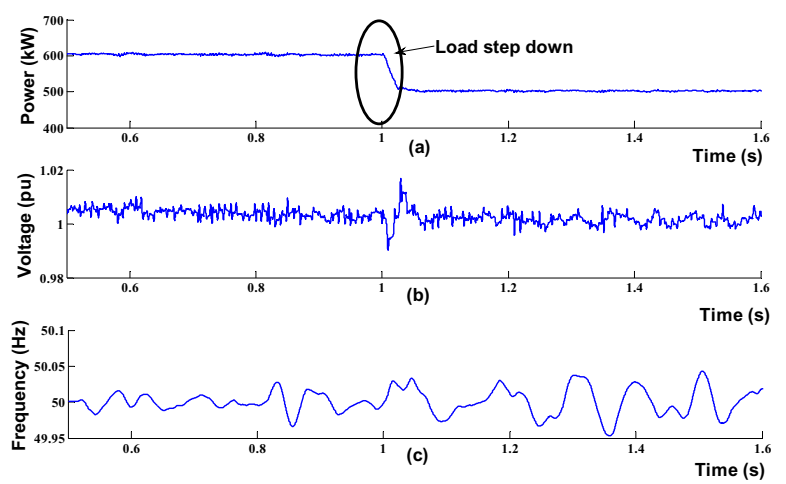

Fig. 5. RAPS responses to a load step down. (a) Real power of load, (b) Stator voltage and (c) Stator frequency
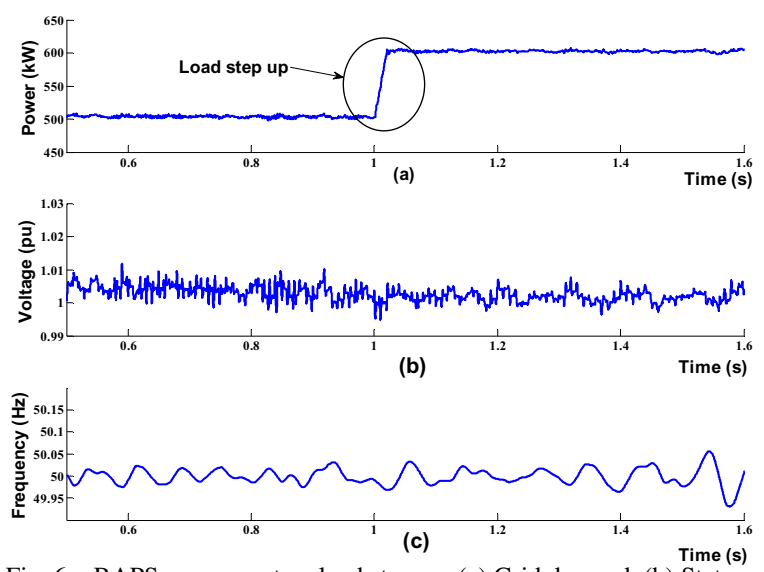

Fig. 6. RAPS responses to a load step up. (a) Grid demand, (b) Stator voltage and (c) Stator frequency 

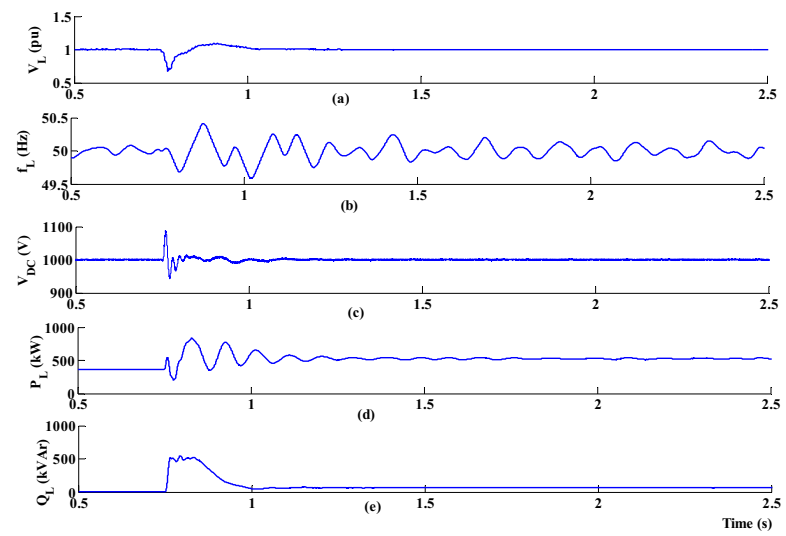

Fig. 7. RAPS responses to an induction motor load. (a) RAPS voltage at PCC, (b) RAPS frequency, (c) DC link voltage, (d) Active power output and (e) Reactive power output

\section{FLuCTUATING WIND TOGETHER WITH AN DYNAMIC LOAD}

In the present study, the harmonic emission level of the DFIG based wind system is examined in relation to the load voltage. As stated earlier, the operation of the DFIG is evaluated under its super synchronous operation mode. The stator current harmonics of the DFIG can be expressed using (9) [10] which excludes the high frequency switching harmonics of the inverter of the line side converter.

$$
f_{s, h}=|1 \pm 6 k s \pm 6 m| f_{s} \quad k, m=0,1,2,3, \ldots \ldots .
$$

The distorted stator current together with the rotor current set up magnetic flux waveforms in the air gap which results a harmonic rich stator voltage. This voltage distortion is propagated to the load (PCC) which in this case is connected through a distribution line.

The harmonic content of the voltages at the PCC and the DFIG busbar have been examined for two different cases:

- case I : Resistive load $(500 \mathrm{~kW})$

- case II : Resistive load $(350 \mathrm{~kW})$ and induction motor load $(150 \mathrm{~kW})$

The variation of the Total Harmonic Distortion (THD) of voltage corresponding to above scenarios are illustrated in Figs. 8 - 9. It is seen that THD levels in both cases are quite similar in relation to the two locations of the network. Upon close examination it can be seen that distortion levels are slightly higher in case I compared to case II. This reduction can be attributed to the dominating impedance of the induction motor.

The frequency spectra of the PCC bus voltage for case I and case II are shown in Figs. 10 - 11 respectively. The interharmonics and non integer harmonics of small magnitudes are seen to occur around $50 \mathrm{~Hz}$ as evident from the above figures. Also a relatively high harmonic voltage can be observed at $80 \mathrm{~Hz}$ in both frequency spectra. This harmonic frequency can be obtained by setting $\mathrm{m}=0, \mathrm{k}=1$ and $\mathrm{s}=0.1$ in (9). The switching harmonics content of the voltage at PCC in case II is shown in Fig. 12. The switching frequency of the back to back PWM converters are used to operate at $2500 \mathrm{~Hz}$. These harmonics represent the substantial magnitude of the frequency spectra at PCC compared to the harmonic at $80 \mathrm{~Hz}$.

According to IEEE 519-1992, the maximum permissible voltage THD level at the PCC should be 5\% whereas the maximum individual voltage harmonics should be less than $3 \%$ [2]. In relation to the present study, the THD values in both cases are higher than 5\%. Also the individual harmonic limits, especially at high frequency range are not satisfying the above limit thus making harmonic filtering a necessity.

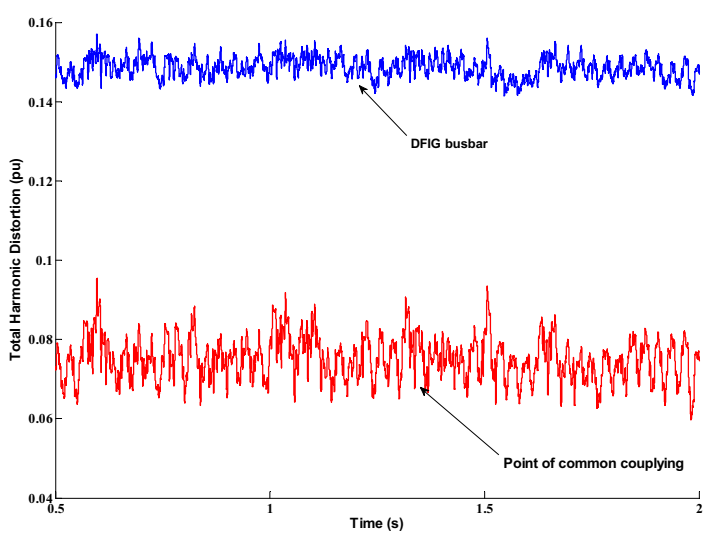

Fig. 8. Case I - THD at PCC and DIFG busbar with resistive load only

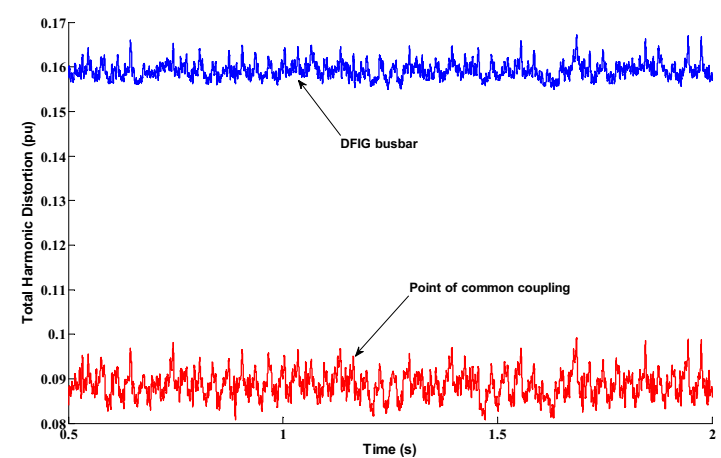

Fig. 9. Case II-THD at PCC and DIFG busbar with resistive load and induction motor load

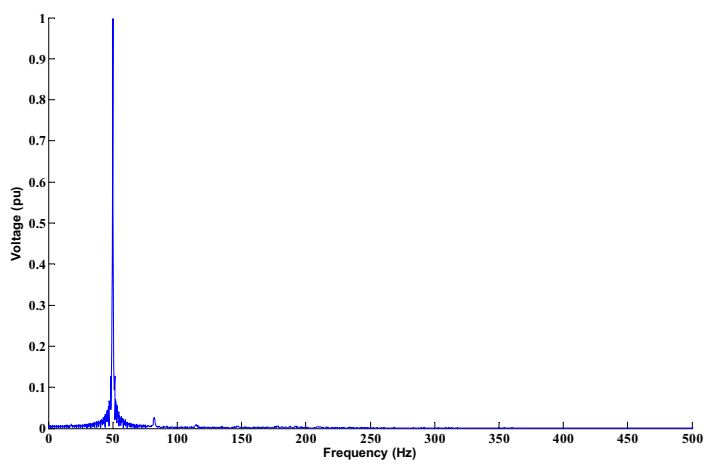

Fig. 10. Frequency spectrum of voltage at PCC with resistive load 


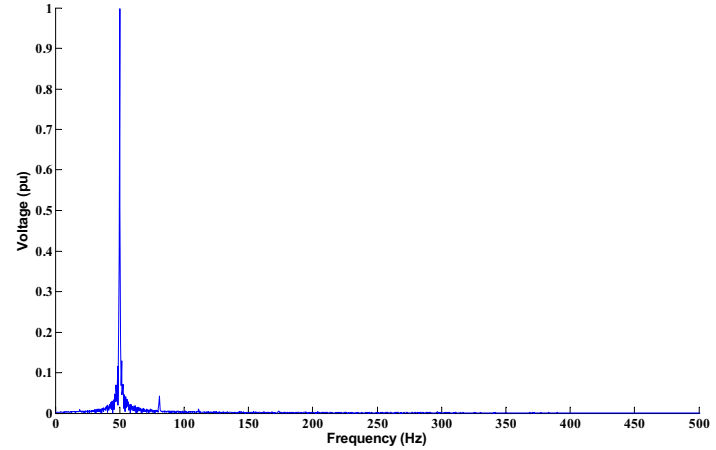

Fig. 11. Frequency spectrum of voltage at PCC with resistive and induction motor load

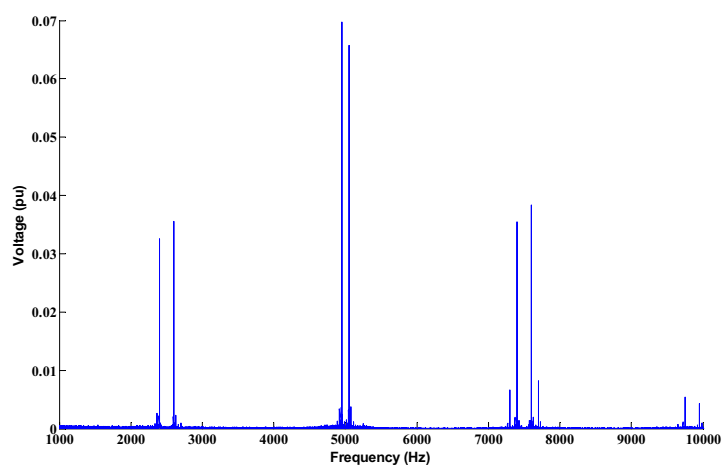

Fig. 12. Switching harmonics of voltage at PCC with resistive and induction motor load

\section{CONCLUSIONS AND FUtURE WORK}

This paper has investigated the voltage quality of a DFIG based remote area power system. The voltage quality of the RAPS system is assessed in terms of its magnitude and frequency under variable wind and different loading conditions. It has been identified that the remote area power system is able to regulate the magnitude and the frequency of the voltage reasonably well under normal conditions. The performance was also observed in relation to the connection of an induction motor where it was seen that the system was reasonably robust. However, further enhancement should be carried out to ensure supply quality which meets the requirements set by standards. The harmonic performance of the DFIG was also examined at the DFIG busbar and the PCC. It was observed that the voltage harmonic levels far exceeded the requirements as set out in the standards. Thus the installation a harmonic filter is necessary to improve the supply quality of the RAPS system. A special attention should be made in removing the lower order harmonics which arise due to the variable slip operation of the DFIG.

The authors are currently working to set up an experimental test bed consisting a $7.5 \mathrm{~kW}$ DFIG to verify the simulated results.

\section{REFERENCES}

[1] T. Senjyu, T. Nakaji, K. Uezato, T. Funabashi, "A Hybrid Power System Using Alternative Energy Facilities in Isolated Island", IEEE Transaction on Energy Conversion, vol. 20, issue 2, June 2005, pp. 406 - 414

[2] V. V. Thong, J. Driesen, R. Belmans, "Overview and Comparisons of Existing DG Interconnection Standards and Technical Guidelines", International Confernece on Clean Electrical Power, May 2007, pp. 51 $-54$.

[3] Technical reoport AS61400.21, "Wind Turbines - Measurement and Assessment of Power Quality Characteristics of Grid Connected Wind Turbines", Standards Australia, 2003.

[4] T. Burton, D. Sharpe, N. Jenkins, and E. Bossanyi, "Wind Energy Handbook", John Wiley and Sons, Ltd, 2001.

[5] D. Forchetti, G. Garcia and M. I. Valla, "Vector Control Strategy for a Doubly-Fed Stand-Alone Induction Generator", 28th Annual Conference on Industrial Electronics, vol. 2, 5-8 Nov. 2002, pp. 991 - 995.

[6] P. Ling, L. Yongdong, C. Jianyun, Y. Guofeng, "Vector Control of a Doubly Fed Induction Generator for Stand-Alone Ship Shaft Generator Systems", International Conference on Electrical Machines and Systems, 8-11 Oct. 2007, pp. 1033 - 1036.

[7] F. Khatounian, E. Monmasson, F. Berthereau, E. Delaleau and J. P. Louis, "Control of a Doubly Fed Induction Generator for Aircraft Application", 29th Annual Conference on Industrial Electronics, vol. 3, 2-6 Nov. 2003, pp. 2711 - 2716

[8] R. Pena, R. Cardenas, G. M. Asher, J. C. Clare, J. Rodriguez and P. Cortes, "Vector Control of a Diesel-Driven Doubly Fed Induction Machine for a Stand-Alone Variable Speed Energy System", 28th Annual Conference on Industrial Electronics, vol. 2, 5-8 Nov. 2002, pp. 985 - 990.

[9] M. Aktarujjaman, M. A. Kashem, M. Negnevitsky and G. Ledwich, "Control Stabilisation of an Islanded System with DFIG Wind Turbine", 1st International Power and Energy Conference, (PECon 2006), pp. 312 - 317, 28-29 Nov. 2006.

[10] S. T. Tentzerakis, S. A. Papathanassiou, "On the Harmonics of the Slip Energy Recovery Drive", IEEE Power Engineering Review, vol. 21, issue 4, April 2001, pp. 55 - 57.

\section{APPENDIX A}

\section{Remote Area Power System Parameters}

\section{Doubly fed induction generator}

Power: 1MW, Stator voltage: $400 \mathrm{~V}$, Frequency: $50 \mathrm{~Hz}$, Stator resistance: $0.00706 \mathrm{pu}$, Stator leakage inductance: $0.171 \mathrm{pu}$, Rotor resistance: $0.005 \mathrm{pu}$, Rotor leakage inductance: 0.156 $\mathrm{pu}$, Magnetising inductance: $2.9 \mathrm{pu}$, Inertia constant: $5.04 \mathrm{pu}$, Number of pole pairs: $3 \mathrm{pu}, \mathrm{DC}$ link capacitance: $10000 \mu \mathrm{F}$.

\section{Low voltage distribution line}

Voltage: $400 \mathrm{~V}$, Resistance: $65 \mathrm{~m} \Omega / \mathrm{km}$, Inductance: $25 \mu / \mathrm{km}$.

APPENDIX B

\section{INDUCTION MOTOR DATA}

\section{Induction motor}

Power: $150 \mathrm{~kW}$, Stator voltage: $400 \mathrm{~V}$, Frequency: $50 \mathrm{~Hz}$, Stator resistance: $0.01818 \Omega$, Stator leakage inductance: $0.00019 \mathrm{H}$, Rotor resistance: $0.009956 \Omega$, Rotor leakage inductance: $0.00019 \mathrm{H}$, Magnetising inductance: $0.009415 \mathrm{H}$, Inertia constant: 2.6, Number of pole pairs: 2.

\section{ACKNOWLEDGEMENT}

This work is supported by the Australian research Council (ARC) and Hydro Tasmania Linkage Grant, LP0669245. The authors gratefully acknowledge the support and cooperation of Hydro Tasmania personnel in providing data and advice on the operation of remote area power supply system. 